\title{
Racismos: das Cruzadas ao século $\mathrm{XX}$, de Francisco Bethencourt. Tradução Luís Oliveira Santos, João Quina Edições. 1. ed. São Paulo: Companhia das Letras, 2018.
}

José Walter Silva e Silva waltersilva@uni9.edu.br

Gustavo Gonçalves Ungaro gustavoungaro@hotmail.com

Paula Anunciação Silva paulaanunciacao@globomail.com

Jane Alcina Prado da Silva jane.prado16@gmail.com

Wellington Camargo Fernandes wellcam2004@yahoo.com.br

Explicar a estrutura significativa dos fenômenos sociais, tendo como referência a trama histórica que proporcionou a sua criação, o imbricamento desses fenômenos com as relações de poder, suas formas de reprodução e os efeitos por eles gerados, é, quase sempre, um desafio da pesquisa científica atingido por uma quantidade não muito generosa de pesquisadores e pesquisadoras. Mas o que dizer quando essa pesquisa tem a sua temporalidade delimitada em dez séculos e um locus que abrange todo o continente europeu, inclusive nas relações mantidas com sociedades colonizadas? Com notável erudição, clareza argumentativa e rigor metodológico é o que se propõe a fazer Francisco Bethencourt nas 603 páginas da sua obra, lançada em 2018 no Brasil, "Racismos: das Cruzadas ao século XX".

Professor de História no Departamento de Estudos Portugueses e Brasileiros do King's College, ex-diretor do Centro Cultural Caloustre Gulbenkian e da Biblioteca Nacional de Portugal, Bethencourt lançou mão de precisos e incontáveis exemplos para concluir que determinadas configurações de racismo - e de maneira geral, o próprio racismo - não podem ser explicadas senão quando compreendidas na sua totalidade, a partir de uma perspectiva histórica de longo prazo que permita comparações, escapando da tentação de delimitar a análise a regiões e a 
grupos sociais recorrentemente vitimizados. Uma opção coerente com a percepção que ele tem do caráter relacional do racismo.

Apoiado nessa metodologia comparada, já nos primeiros parágrafos da Introdução e de forma extremamente didática, o autor evidencia o domínio dos rigores da pesquisa acadêmica, esclarecendo, como poucas obras do gênero, os problemas da pesquisa, os argumentos utilizados e a hipótese, segundo a qual, "ao longo da história, o racismo na forma de preconceito étnico associado a ações discriminatórias foi motivado por projetos políticos” (p. 22). Também de forma bastante direta, Bethencourt anuncia, já no primeiro parágrafo, o ineditismo do seu pensamento ao romper com o entendimento "de que a teoria das raças antecedeu o racismo" (p. 21) e vai mais além: contesta a ideia de que o racismo foi inventado na Antiguidade Clássica e "rejeita a ideia do racismo como fenômeno inato partilhado por toda a humanidade" (ibidem).

"Racismos: das Cruzadas ao século XX" está estruturado em cinco partes cronologicamente organizadas. A "Parte 1", denominada As Cruzadas, apresenta ao leitor o ponto de partida histórico-geográfico da obra: as constantes invasões da Europa Ocidental pelos povos chamados "bárbaros" e a consequente necessidade de novas designações étnicas, além da institucionalização das Cruzadas como projeto político do desenvolvimento da cristianização. Mais do que preservar e expandir o território católico por meio da conversão de "infiéis", tal projeto político promoveu antigos e novos preconceitos que deram sentido às campanhas beligerantes voltadas à expulsão dos mulçumanos da Sicília, Península Ibérica e Oriente Médio. O resultado foi a criação de novas discriminações pautadas principalmente na religião, mas também em tipologias humanas e marcadores de identidade, como a cor da pele, vestuário, costumes, ornamentos, animais domesticados, língua, ascendência étnica...

Contudo, o projeto político discriminatório das Cruzadas não ficou restrito à religião nem às conquistas e reconquistas territoriais que promoveram a sua criação. Pelo contrário, inflado pelas explorações oceânicas, ele passou a ser tomado como referência para justificar processos de dominação e expansão colonial para o mundo a ser conquistado nas décadas do século XVI. As terras já conhecidas e os novos domínios passaram a ser personificados por geógrafos e cartógrafos a partir de percepções europeias que os colocavam no centro do mundo. Para tanto, tal produção intelectual lançava mão dos citados marcadores de identidade, destacadamente a cor da pele, que passou a assumir relevância cada vez maior na classificação comparada com a Europa branca e civilizada. Esse é o tema que Bethencourt aborda, na "Parte II", denominada Exploração Oceânica. 
A análise dos projetos políticos das principais potências coloniais, sempre entrelaçados com sistemas de categorização baseado na cor da pele, foi apresentada pelo autor na "Parte III", denominada Sociedades Coloniais. A análise evidencia que as dialéticas relações estabelecidas entre os colonizadores e os povos originários dos territórios conquistados produziram modelos de colonização distintos, ainda que o colonizador tenha sido o mesmo. Se o dominador exportou elementos da sua cultura, como a língua, as leis e as tecnologias, teve, também, de adaptá-los às novas condições geográficas e culturais das colônias que estabeleciam. A síntese dos processos colonizadores envolveu, portanto, a criação de novos preconceitos étnicos e raciais, promovidos por novas taxionomias étnicas e hierarquias sociais; a institucionalização política e comercial do trabalho escravo (negro); bem como mudanças nas opiniões europeias preconcebidas, resultado da inevitável integração das populações nativas com as neófitas estruturas coloniais e da reorganização da economia e da sociedade locais.

Teorias de Raça é o título e o tema central da "Parte IV", onde Bethencourt faz uma minuciosa apresentação do pensamento e das experiências realizadas por estudiosos da história natural e da variedade humana no período de 1730 a 1840. Tais estudos e metodologias, sustentados por argumentações de natureza geográfica, biológica, racial e cultural, serão radicalizados pela pesquisa científica na década seguinte, devido a ascensão do nacionalismo étnico. Após analisar as propostas dos teóricos do Racialismo Científico, denominação dada por Bethencourt a esse movimento de radicalização racial da ciência, o autor aponta um conjunto de acontecimentos econômicos, políticos e sociais, ocorridos na segunda metade do século XIX, que contribuíram para o ressurgimento de projetos políticos nacionalistas e para a produção de novos questionamentos acerca das relações interétnicas, além de novas categorias de análise para a produção de teorias de raças. É neste contexto histórico que as ideias contestatórias de Darwin, em relação a dogmas do racialismo científico, forçarão a "adaptação dos preconceitos relativos à ascendência étnica e às construções raciais” (p. 408), posto que não seriam mais sustentáveis as ideias de "escravo natural, além das características físicas e mentais imutáveis" (ibidem). À revelia do cientista, o darwinismo trouxe "para o campo natural a competição social e a exploração colonial" (p. 417).

A "Parte V", denominada Nacionalismo e mais além, aprofunda a relação causal dos novos projetos políticos nacionalistas com processos de reinvenção e afirmação de identidades. Dessa forma, não serão outros protagonistas do redesenho geopolítico, ocorrido no final do século XIX e por todo o século XX, senão antigos marcadores identitários, como raça, língua e, sobretudo, religião, que se associaram a teorias racialistas para redefinir a compreensão de direitos humanos 
e exterminar grupos sociais e étnicos indesejáveis. Pautado nesta perspectiva, o autor analisa a incorporação dos preconceitos quanto à ascendência étnica combinados com ações discriminatórias na implantação dos projetos políticos da Turquia, da Alemanha, da Namíbia e de Ruanda, países que o fizeram por meio do genocídio. Já países como os Estados Unidos, África do Sul, China, Japão, Índia e Brasil também foram examinados, porém sem o entendimento de que os seus projetos políticos tivessem descambado, segundo o autor, para o genocídio. Contudo, aqui vale uma ponderação. Como não caracterizar também como processo genocida, a implantação do projeto político da metrópole portuguesa no Brasil Colônia, que promoveu a dizimação e o extermínio sistemático de muitos povos indígenas brasileiros? Não estariam também essas culturas incluídas na mesma categoria daqueles que puseram em risco as existências dos povos armênio, judeu, hererós e tutsi? Como não considerar genocídio a eliminação de aproximadamente $90 \%$ da população dos povos ameríndios no decorrer do século XVI, por portugueses e espanhóis? (p. 259).

Poucos são os pontos passíveis de contestação nesta obra elaborada por Bethencourt, contudo, duas questões de ordem teórica devem ser, no mínimo, problematizadas. Se o assassinato e o grave comprometimento físico, mental, cultural e populacional de grupos específicos são atos considerados significativos e indicadores de genocídio pela Organização das Nações Unidas (p. 475), então parece ter sido um equívoco analítico do autor não incluir os projetos ibéricos nas Américas no rol dos projetos políticos genocidas. Já a segunda questão refere-se à visível ênfase do autor sobre a determinação da esfera política nos processos históricos de longa duração. O tratamento do autor a essa dimensão, tomada também por ele como categoria analítica, deixa a entender que o político sobrepõe-se sempre às questões de natureza econômica, ainda que este elemento esteja vivamente presente em sua análise. De fato, neste último aspecto, não se trataria de um equívoco, mas de uma opção por certa abordagem teórica, o que não compromete em nada a proposta do autor, apenas a direciona para uma determinada perspectiva.

Explicitar a motivação política, calcada na ânsia por mais poder de grupos dominantes autoritários, e afastar a imprecisa e equivocada noção de que os racismos poderiam ser um elemento linearmente presente na história da evolução da humanidade, certamente ajuda a diagnosticar a injusta mazela, artificialmente erigida e ferozmente imposta, que vitima negros, judeus, índios e tantas outras etnias e pessoas rotuladas a fim de serem inferiorizadas, numa espiral absurda alimentada por ódios infundados e desinformação enviesada, que pode e deve ser enfrentada e superada, para a prevalência da dignidade essencial de todo ser humano. 
Ao terminar a leitura deste "Racismos: das Cruzadas ao século XX", o leitor certamente perceberá como foi conduzido por categorias e episódios históricos com maestria. Constatará ter em mãos uma obra de referência, indispensável para auxiliá-lo na percepção de processos discriminatórios nos projetos políticos nacionais; na compreensão da gênese dos discursos de ódio étnico tão difundidos a partir dos fluxos migratórios mundiais e, finalmente, na explicação da emergência de discursos e lideranças ultraconservadoras por todo o mundo. Esta obra traz particular contribuição para ampliar o conhecimento, quebrar resistências e desconforto que muitos professores têm ao discutir o tema, incrementar e diversificar projetos escolares, especialmente com os estudantes da Educação Básica, inclusive para cumprir a previsão da Lei n. 9394/96, alterada pela Lei n. 10.639/2003, que determina a obrigatoriedade do ensino da história e da cultura africana e afro-brasileira na formação do povo brasileiro. 